\title{
Vergleichende Untersuchung über die Zusammensetzung des Caseins aus Frauen- und Kuhmilch.
}

\author{
Von
}

Emil Abderhalden und Leo Langstein.

(Aus dem physiologischen Institute der tierärztlichen Hochschule und dem KaiserinAuguste-Victoria-Haus zur Bekämpfung der Säuglingsterblichkeit im Deutschen Reiche.)

(Der Redaktion zugegangen am 21. März 1910.)

Die Eiweißkörper der Milch fesseln unser Interesse in ganz besonders hohem Grade, sind sie es doch, aus denen der wachsende Säugling all die mannigfaltigen aus Eiweiß bestehenden - flüssigen, halbfesten und festen - Gebilde aufbaut. Die Kenntnis der Zusammensetzung der Proteine der Milch gibt uns einen Einblick in ihre Umwandlungen, ehe sie in körpereigene Eiweißstoffe übergehen. Zurzeit sind wir noch nicht in der Lage, einzelne Eiweißkörper nach ihrer Struktur zu vergleichen, wir müssen uns damit begnügen, die Art der Bausteine der verschiedenartigen Proteine festzustellen. Schon bei der Vergleichung der Mengen der einzelnen Bausteine der Aminosäuren -, die bei der totalen Hydrolyse erhalten werden, stößt man auf Schwierigkeiten. Es gibt zurzeit keine Methode, die für alle Aminosäuren eine quantitative Bestimmung zuläßt. Eine reiche Erfahrung hat jedoch gezeigt, daß es gelingt, bei ganz gleichartiger Ausführung der Estermethode stets innerhalb enger Grenzen annähernd dieselben Mengen von Aminosäuren aus dem gleichen Protein zu erhalten.

Es schien uns nun von Interesse, festzustellen, ob aus Menschenmilch dargestelltes Casein dieselben Aminosäuren und etwa in denselben Mengenverhältnissen aufweist, wie das aus Kuhmilch gewonnene Casein. Für Tyrosin und Glutaminsäure fanden wir fast identische Werte. Ferner konnten wir in beiden Caseinarten kein Glykokoll feststellen. Für die übrigen 
Monoaminosäuren wurden ebenfalls sehr ähnliche Werte in beiden Fällen gefunden. Die to ta le Hydrolyse des aus Frauenmilch gewonnenen Caseins hat somit keine sicher feststellbaren Unterschiede gegenüber dem Kuhmilchcasein ergeben. Daß daraus noch lange nicht gefolgert werden darf, daß nunmehr beide Caseinarten als identisch zu betrachten sind, ist bereits wiederholt betont worden. Es können z. B. die einzelnen Bausteine in ganz verschiedener Reihenfolge verknüpft sein. Hier muß die partielle Hydrolyse einsetzen.

\section{Experimenteller Teil.}

\section{Darstellung des Caseins aus Frauenmilch nach Enge1. 1)}

$\mathrm{Zu}$ der 5 fach verdünnten Milch wird so viel Essigsäure zugegeben, daß auf $100 \mathrm{ccm}$ unverdünnter Milch etwa $70 \mathrm{ccm}$ 1/10-n.-Essigsäure kommen.

Täglich wurden 21 verarbeitet. Je 11 Frauenmilch?) wurden mit $700 \mathrm{ccm} 1 / 10-n$.-Essigsäure versetzt und in einer großen Flasche mit Wasser auf $5000 \mathrm{ccm}$ aufgefüllt, geschüttelt und 2-3 Stunden im Eisschrank stehen gelassen. Der ganze Inhalt wurde dann in ein großes Gefäß hineingegossen und dieses in ein Wasserbad von $40-45^{\circ}$ hineingestellt. Nach einer 1/4 Stunde, nachdem die Flüssigkeit die Temperatur von etwa $30^{\circ}$ angenommen hatte, wurde durch ein großes, doppeltes Filter filtriert. Der Niederschlag, ein Gemenge von Casein und Fett, durch gelösten Milchzucker und Albumin verunreinigt, wurde vom Filter in eine Soxhlet-Hülse abgeschabt. Nacheinander wurde mit Alkobol und absolutem Alkohol gewaschen und im Ätherextraktionsapparat fast vollkommen vom Fett befreit.

Das Rohprodukt (4-41/2 g auf 21 Milch), das schön weiß aussah und an der Luft zu einem Pulver zerbröckelte, wurde in einer Kugelmühle fein gepulvert und nun in einer

1) Engel, Eine einfache Methode der quantitativen Abscheidung des Caseins aus genuiner Frauenmilch. Biochem. Zeitschrift, Bd. XIV, S. 234, 1908.

2) Es wurde frische Frauenmilch verwendet, die längstens einen Tag im Eiskasten gestanden hatte. Für die Hilfe bei der Darstellung danken wir Herrn Dr. Edelstein. 
großen Zentrifuge solange mit schwach-essigsaurem Wasser, Alkohol und Äther gewaschen, bis das Casein frei von Milchzucker und Fett war.

Das Präparat wurde im Exsikkator über Schwefelsäure getrocknet.

Aus 170 g Rohprodukt (entsprechend etwa 86 l Frauenmilch) wurden $120 \mathrm{~g}$ reines Casein gewonnen.

I. $2,0582 \mathrm{~g}$ Substanz verloren bei $105^{\circ} 0,1498 \mathrm{~g} \mathrm{H}_{2} \mathrm{O}$, also: $7,28 \% \mathrm{H}_{2} \mathrm{O}$.

II. 0,5776 > > > > $105^{\circ} 0,0452$ > > $7,82 \%$,

III. $4,0190 \gg>>105^{\circ} 0,3206 \gg>7,97 \%$ >

Aschenbestimmung:

$0,3398 \mathrm{~g}$ Substanz ergaben $0,0033 \mathrm{~g} \mathrm{Asche}=\mathbf{0 , 9 7} \%$.

Hydrolyse des Caseins aus Frauenmilch.

Wir verwendeten zum Nachweis der einzelnen Monoaminosäuren $95 \mathrm{~g}$ reines Casein. Die totale Hydrolyse wurde in der gewohnten Weise durch 16 stündiges Kochen des Caseins mit der fünffachen Menge 25\% iger Schwefelsäure herbeigeführt. Die Hydrolysenflüssigkeit färbte sich dunkelbraun. Beim Filtrieren hinterblieben $0,75 \mathrm{~g}$ einer melaninartigen Masse. Nach quantitativer Entfernung der Schwefelsäure mit Baryt engten wir das Filtrat des Baryumsulfatniederschlages unter vermindertem Druck bis zur beginnenden Krystallisation ein. Der Baryumsulfatniederschlag wurde wiederholt mit heißem Wasser ausgekocht. Die Waschwässer engten wir ebenfalls unter vermindertem Druck ein. Zur weiteren Krystallisation des Tyrosins wurde bei gewöhnlichem Druck auf dem Wasserbade eingeengt. Die Menge des Rohtyrosins betrug 5,2\% des angewandten Caseins. Nach dem Umkrystallisieren aus heißem Wasser unter Anwendung von Tierkohle verblieben 4,58\% reines Tyrosin.

Die Mutterlauge des Tyrosins diente zur Abscheidung der Glutaminsäure in Form ihres Chlorhydrates. Nach dem Einleiten von gasförmiger Salzsäure trat bald eine dunkelbraune Färbung der Flüssigkeit auf, welche sich noch vermehrte, als die Lösung konzentriert wurde. Die Abscheidung der salzsauren Glutaminsäure erfolgte erst, nachdem die Flüssigkeit 
auf ein kleines Volumen gebracht war. Sie war auch dann noch sehr unvollständig. Wir lösten deshalb den Krystallbrei wieder in Wasser und verdampften die gesamte Flüssigkeit unter vermindertem Druck zur Trockene. Der Rückstand wurde in Wasser gelöst und mit soviel Kupferoxydul geschüttelt, bis die Lösung sich grünblau färbte. Nun wurde filtriert, der Rückstand gut gewaschen und im Filtrat das gelöste Kupfer mit Schwefelwasserstoff entfernt. Das Filtrat vom Kupfersulfid war hellgelb gefärbt. Es wurde eingeengt. Beim Einleiten von gasförmiger Salzsäure in die mäßig konzentrierte Lösung gelang es nun leicht, die salzsaure Glutaminsäure in großen, farblosen und ganz reinen Krystallen quantitativ abzuscheiden. Die Ausbeute an reiner Glutaminsäure betrug 10,95\%.

Wir haben die Bestimmung des Tyrosins und der Glutaminsäure mit $40 \mathrm{~g}$ Casein wiederholt und fanden $\mathbf{4 , 4 6 \%}$ Tyrosin und 10,78\% Glutaminsäure.

Die Mutterlauge der salzsauren Glutaminsäure beider Bestimmungen diente zur Darstellung der übrigen Monoaminosäuren mittels der Estermethode. Die Durchführung der Veresterung, der Esterinfreiheitsetzung, Destillation der freien Ester und ihrer Verseifung bot keine Besonderheiten. Die Trennung der Aminosäuren in den einzelnen Fraktionen erfolgte in der üblichen Weise.

Erhalten wurden:

Alanin: Es wurde identifiziert durch seine spezifische Drehung $[\alpha]_{80^{\circ}}^{\mathrm{D}}=+9,5^{\circ}$ und seine Analyse:

$0,1779 \mathrm{~g}$ Substanz brauchten $20,35 \mathrm{ccm} \mathrm{n} / 10-\mathrm{H}_{2} \mathrm{SO}_{4}$.

Berechnet für $\mathrm{C}_{8} \mathrm{H}_{7} \mathrm{NO}_{2}$ :

Gefunden: $15,73 \% \mathrm{~N}$. $16,0 \% \mathrm{~N}$.

Valin: Sein Drehungsvermögen war $+25,85^{\circ}$ in $20 \%$ iger Salzsäure.

$0,2420 \mathrm{~g}$ Substanz brauchten $21,0 \mathrm{ccm} \mathrm{n/10-}-\mathrm{H}_{2} \mathrm{SO}_{4}$.

Berechnet für $\mathrm{C}_{5} \mathrm{H}_{11} \mathrm{NO}_{2}$ :

Gefunden: $11,96 \% \mathrm{~N}$.

$12,1 \% \mathrm{~N}$.

Leucin: $[\alpha]_{20^{\circ}}^{\mathrm{D}}=+14,25^{\circ}$ in $20 \%$ iger Salzsäure.

$0,2780 \mathrm{~g}$ Substanz brauchten $21,0 \mathrm{ccm} \mathrm{n} / 10-\mathrm{H}_{8} \mathrm{SO}_{4}$.

Berechnet für $\mathrm{C}_{6} \mathrm{H}_{18} \mathrm{NO}_{2}$ :

Gefunden:

$10,69 \% \mathrm{~N}$.

$10,5 \% \mathrm{~N}$. 
12 Emil Abderhalden und Leo Langstein, Über Casein.

Bei der Trennung von Valin und Leucin waren Verluste unvermeidlich. Isoleucin war unzweifelhaft auch vorhanden.

Serin konnte nur in Spuren isoliert und durch seinen Zersetzungspunkt identifiziert werden. Sein Nachweis darf daher noch nicht als ganz gesichert betrachtet werden.

Asparaginsäure:

0,2224 g Substanz brauchten $16,95 \mathrm{ccm} \mathrm{n} / 10-\mathrm{H}_{2} \mathrm{SO}_{4}$.

Berechnet für $\mathrm{C}_{4} \mathrm{H}_{7} \mathrm{NO}_{4}$ :

Gefunden:

$10,52 \% \mathrm{~N}$.

$10,7 \% \mathrm{~N}$.

Glutaminsäure:

$0,3300 \mathrm{~g}$ Substanz brauchten $22,3 \mathrm{ccm} \mathrm{n} / 10-\mathrm{H}_{2} \mathrm{SO}_{4}$.

Berechnet für $\mathrm{C}_{5} \mathrm{H}_{9} \mathrm{NO}_{4}$ : Gefunden:

$9,52 \% \mathrm{~N}$.

$9,46 \% \mathrm{~N}$.

Phenylalanin:

$0,1672 \mathrm{~g}$ Substanz brauchten $10,5 \mathrm{ccm} \mathrm{n} / 10-\mathrm{H}_{2} \mathrm{SO}_{4}$.

Berechnet für $\mathrm{C}_{9} \mathrm{H}_{11} \mathrm{NO}_{\mathbf{2}}$ :

$$
8,48 \% \mathrm{~N} \text {. }
$$

Gefunden:

$8,7 \% \mathrm{~N}$.

Prolin ist in der üblichen Weise abgetrennt und identifiziert worden.

Berechnet auf $100 \mathrm{~g}$ aschefreies, bei $100^{\circ}$ bis zur Gewichtskonstanz getrocknetes Casein ergaben sich folgende Ausbeuten an den einzelnen Aminosäuren.

\begin{tabular}{|c|c|c|c|}
\hline Alanin & $1,2 \mathrm{~g}$ & Glutaminsäure & $10,95 \mathrm{~g}$ \\
\hline Valin & 1,3 " & Phenylalanin & 2,8 \\
\hline Leucin & $8,8 *$ & Tyrosin & 4,58 \\
\hline Asparaginsäure & 1,0 & Prolin & 2,85 \\
\hline
\end{tabular}

